3. E.C.G. changes suggestive of ischaemia were present preoperatively in 52 per 1,000 , and similar changes developed postoperatively in a further 38 per 1,000 who had a normal E.C.G. before operation. A total of 114 per 1,000 had either ischaemic changes or infarction.

4. There is an apparent association between these E.C.G. changes and operation on the biliary tract, thyroid, upper abdomen, and herniae.

5. Associations also appear to exist with long operations, with preoperative hypertension, and possibly with obesity.

6. There was no clear association between the E.C.G. changes and the type of anaesthetic, the occurrence of hypotension during the operation, and such factors as the stay in hospital and postoperative complications due to the surgical diseases.

7. There was no clinical evidence of cardiac disturbance associated with the E.C.G. changes, except in one patient who developed postoperative myocardial infarction.

8. Of all the patients in this study (506) 98 (20\%), or 196 per 1,000 , had some abnormality of the E.C.G. or had a history suggestive of ischaemic heart disease while in hospital.

9. The study also revealed that $30 \%$ of our patients were moderately or severely hypertensive, and that $12 \%$ were more than $20 \%$ overweight.

10. Although there was little clinical evidence of cardiac disturbance which could be associated with the great majority of these E.C.G. changes, nevertheless the proportion of surgical patients involved is not small. It is important, therefore, to know with more certainty than at present whether these E.C.G. changes indicate an effect on the prognosis of the patient. Long-term follow-up studies are needed.

11. If the E.C.G. changes should prove to be of importance to the surgical team then every patient should have a preoperative and postoperative E.C.G. as well as a much better general clinical assessment than they do at present. In the meantime particular attention should be paid to the "markers" we have indicated, and perhaps more use should be made of E.C.G. monitors.

\section{Summary}

A total of 506 surgical patients aged 35 to 66 years were studied from the point of view of myocardial ischaemia and ischaemic heart disease. Myocardial infarction was present in eight patients preoperatively, and developed in three after operation. In addition, E.C.G. changes suggestive of ischaemia were present preoperatively in $26(5 \%)$, and developed postoperatively in a further $19(4 \%)$.

There was an apparent association between these changes and certain operative procedures, operations of longer duration, and preoperative hypertension.

It is important to know whether these E.C.G. changes indicate an effect on the prognosis of the patient. In all, $98(20 \%)$ patients had some abnormality of the E.C.G. or a history suggestive of ischaemic heart disease. Long-term follow-up studies are needed.

We would like to acknowledge the invaluable collaboration of Mr. J. Morgan and the staff of the Medical Records Department and of Miss D. M. Francis and the staff of the E.C.G. Department at the Royal Infirmary, Cardiff, and also to record our gratitude to many colleagues and the ward sisters who assisted us during this study. We gratefully acknowledge the help of the United Cardiff Hospitals Endowment Fund in defraying some of the expenses of this study.

\section{REFERENCES}

Arkins, R., Smessaert, A. A., and Hicks, R. G. (1964). F. Amer. med. Ass., 190, 485.

Blackburn, H., Keys, A., Simonson, E., Rautaharju, P., and Punsar, S. (1960). Circulation, 21, 1160.

Chamberlain, D. A., and Edmonds-Seal, J. (1964). Brit. med. f., 2, 784.

Davies, L. G. (1958). Brit. Heart f., 20, 153.

Dawber, T. R., Moore, F. E., and Mann, G. V. (1957). Amer. 7. publ. Hlth, 47, Suppl. p. 4.

dePeyster, F. A., Paul, O., and Gilchrist, R. K. (1952). Arch. Surg., 55, 448.

Documenta Geigy Scientific Tables, 1962, edited by K. Diem, 6th ed., p. 623. Geigy, Manchester.

Driscoll, A. C., Hobika, J. H., Etsten, B. E., and Proger, S. (1961). New Engl. F. Med., 264, 633 .

Etsten, B. E., and Proger, S. (1955). 7. Amer. med. Ass., 159, 845.

Higgins, I. T. T., Cochrane, A. L., and Thomas, A. J. (1963). Brit. 7. prev. soc. Med., 17, 153 .

Master, A. M., and Rosenfeld, I. (1964). F. Amer. med. Ass., 190, 494.

Mushin, W. W., Rendell-Baker, L., Lewis-Faning, E., and Morgan, J. H. (1954). Brit. F. Anaesth., 26, 298.

Thomas, A. J., Cochrane, A. L., and Higgins, I. T. T. (1958). Lancet, 2, 540 .

Topkins, M. J., and Artusio, J. F., jun. (1964). Anesth. Analg. Curr. Res., 43, 716.

\title{
Surgical Management of Prolapse in Elderly Women
}

\author{
EUAN G. ROBERTSON,* M.B., B.S., D.OBST.R.C.O.G. ; JAMES K. RUSSELL, † M.D., F.R.C.o.G.
}

In a previous communication (Russell, 1961) attention was drawn to some of the serious complications that may follow the use of vaginal pessaries in the management of prolapse in elderly women. During 1957-61 we saw in the gynaecological department several patients with cancer of the vagina, ulcerative vaginitis, pelvic cellulitis, and rectal or vaginal fistulae ; all related to the prolonged use of some form of vaginal pessary. Over the same period other elderly women were admitted to the department for treatment when they found that with advancing age their pessaries became difficult to insert and remove (because of senile vaginitis and narrowing of the introitus). And there were some whose pessaries in time failed to control the prolapse, which then became ulcerated, oedematous, and infected. Other writers have reported similar troubles associated with the prolonged use of pessaries. A vesico-vaginal fistula was caused by a Napier cup-and-stem pessary (McCullagh, 1955 ; McElin and Paalman, 1959), and Binnie (1964) reported the cases of two patients who suffered strangulation of a complete procidentia through a watch-spring pessary. Another patient retained a pessary in position for 62 years and did not know of its existence (Pritchard, 1961).

\section{Present Investigation}

In the belief that elderly women stand operative treatment surprisingly well it has long been the custom of the gynaeco-

\footnotetext{
* Gynaecological Registrar, Royal Victoria Infirmary, Newcastle upon

† Professor of Obstetrics and Gynaecology, University of Newcastle upon Tyne.
} 
logical staff of this hospital to offer surgery where at all possible for prolapse rather than use vaginal pessaries. In order to test the validity of this policy we have carried out a retrospective study of all patients over the age of 75 who have been operated on for prolapse during the period 1960 to 1964 inclusive. For comparison we have taken at random a similar number of women under the age of 65 who had vaginal plastic operations carried out during the same five-year period. The age distribution of the 50 patients in each group is shown in Figs. 1 and 2. Slightly more of the control group than the elderly group had had more than three children; three patients among the elderly and one in the control group were nulliparous. A high proportion of the elderly group had major degrees of prolapse-21 bad complete procidentia, often with ulceration, and a further

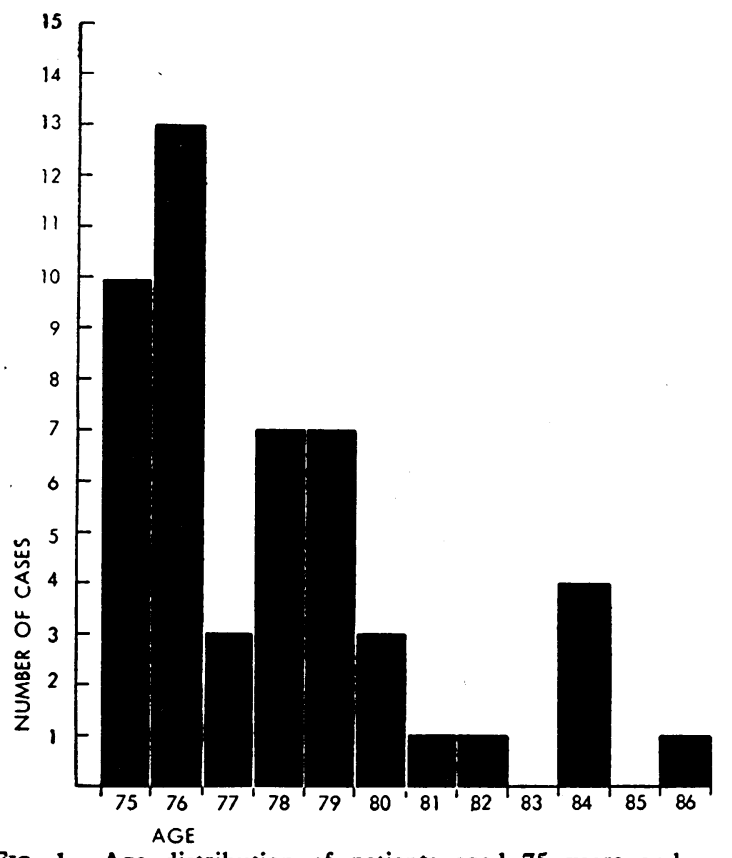

FIG. 1.-Age distribution of patients aged 75 years and over.

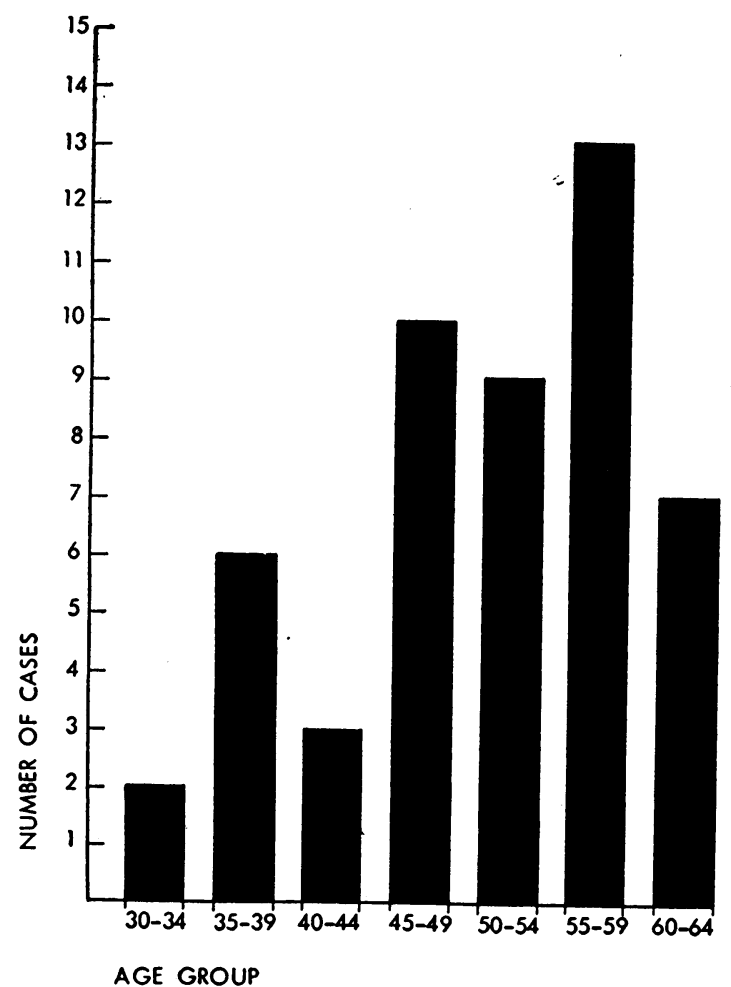

FIG. 2.-Age distribution of control series of patients.
16 had a significant degree of cystocele and rectocele with second-degree descent of the cervix. Against this only 18 of the younger patients had a significant degree of prolapse and only six of these had a complete procidentia. Fourteen of the elderly patients but only one of the younger group had had symptoms for over 10 years. Twelve patients in the over-75 age group had worn a pessary for periods varying from two months to 26 years; none of the younger women had ever worn a pessary.

As might be expected more of the elderly women had concomitant disease (Table I).

Table I.-Concomitant Disease in Both Groups of Patients

\begin{tabular}{|c|c|c|c|c|c|c|}
\hline \multicolumn{5}{|c|}{ Concomitant Disease } & Over 75 & Control \\
\hline $\begin{array}{l}\text { Hypertension } \\
\text { Pernicious anaemia } \\
\text { Diabetes mellitus } \\
\text { Rheumatoid arthritis } \\
\text { Myocardial infarction } \\
\text { Senile dementia . } \\
\text { Carcinoma of breast } \\
\text { Pseudobulbar palsy } \\
\text { Chronic bronchitis }\end{array}$ & $\begin{array}{l}\cdots \\
\cdots \\
\cdots \\
\cdots \\
\cdots \\
\cdots\end{array}$ & $\begin{array}{l}\cdots \\
\cdots \\
\cdots \\
\cdots \\
\cdots \\
\cdots\end{array}$ & $\begin{array}{l}\cdots \\
\cdots \\
\cdots \\
\cdots \\
\cdots \\
\cdots\end{array}$ & $\begin{array}{l}\because \\
\because \\
\because \\
\cdots \\
\cdots \\
\therefore\end{array}$ & $\begin{array}{r}15 \\
3 \\
2 \\
2 \\
1 \\
1 \\
1 \\
1 \\
0\end{array}$ & $\begin{array}{l}\mathbf{5} \\
\mathbf{1} \\
0 \\
0 \\
0 \\
0 \\
0 \\
1 \\
0 \\
\mathbf{2}\end{array}$ \\
\hline
\end{tabular}

All patients in the elderly group were carefully assessed by a physician and by an anaesthetist before admission, and a decision about suitability for operation was made after consultation between them and the gynaecologist. The various types of operation carried out on both groups of patients are shown in Table II. Because of the increased number of patients with severe degrees of prolapse more major vaginal surgery was carried out in the elderly than in the control group. For the older women the standard anaesthetic was induction with thiopentone, suxamethonium, and nitrous oxide followed by nitrous oxide and ether or halothane.

TABLE II.-Type of Operation in Both Groups of Patients

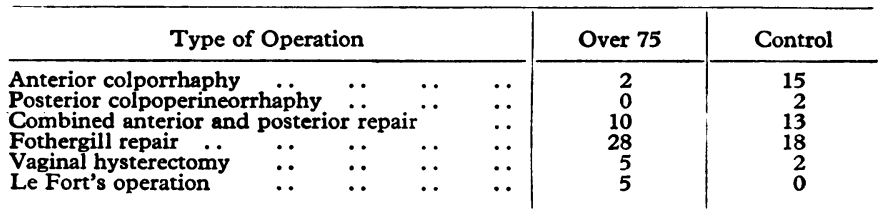

The significant postoperative complications suffered by the two groups of patients are shown in Table III. One elderly woman died from a cerebrovasc'llar accident (she was known to suffer from pseudobulbar palsy) on the eighth day after operation. Apart from this fatality there was little difference between the two groups. The elderly women spent more time in hospital before and after operation. They were admitted earlier for general physical assessment and also to ensure that the vaginal and pelvic tissues were in the best possible condition at the time of operation. Those with ulcerated procidentia

TABLE III.-Postoperative Complications in Both Groups of Patients

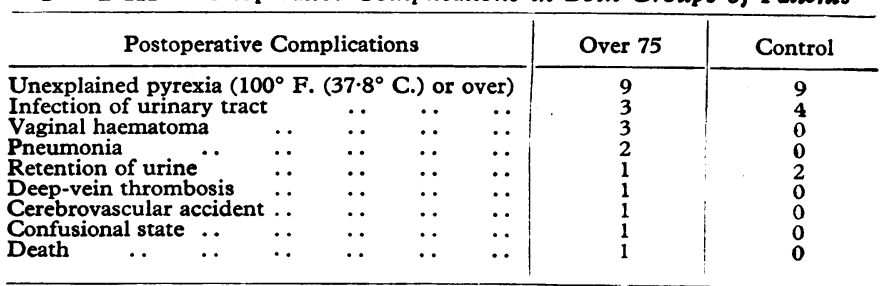

were admitted a fortnight before operation, and after reduction of the procidentia the vagina was packed with gauze soaked in either acriflavine or petroleum jelly ; the patients also received a small dose of oestrogen each day in order to improve the quality of vaginal tissues. The average stay in hospital was 4.9 days before operation and 12.9 days afterwards for the 
elderly group and 2.6 and 11.5 days respectively for the control group. Care was taken with the elderly women to ensure that they were ambulant before discharge from the ward, and that there were adequate facilities at home for their aftercare. The domiciliary nursing service and the family doctor were notified, and were asked to continue intensive care for a short time after discharge.

\section{Follow-up}

It is our standard practice for all patients who have had a prolapse operation to be seen at the follow-up clinic three months after discharge from hospital. One patient in the elderly group had died in the immediate postoperative period, and four others were unable to attend because of incapacity, two having been admitted to geriatric units with confusional states and the remaining two having chronic ailments which made it inadvisable for them to attend the clinic. This meant that out of the original 50 patients only 45 were able to attend at three months, although all those in the control group were seen at this time. Eighty-six per cent. of the elderly group were assessed as having a good result. One patient had a poor operative result and continued to complain of stress incontinence. A second patient had a recurrence of a complete procidentia six weeks after the primary operation; this was later repaired with a satisfactory result. Two patients had developed cystoceles, and the remaining two had developed enteroceles, but no further operative treatment was thought necessary. A similar result was reported in the control group, $86 \%$ being assessed as having had a satisfactory result. No further arrangements were made to see the patients in this group again for follow-up.

One of us (E. G. R.) made special arrangements for long-term assessment of the elderly group of patients. In order to avoid embarrassment to the relatives of these patients a questionary was sent to the family doctors asking whether the patient was still alive, whether she had had any recurrence of the prolapse, and if she would be healthy enough to attend for interview and examination. Two patients were known to have died in hospital in the intervening years, and so only 47 questionaries were sent out. Replies were received to 43 of these. One patient had moved from the district and was lost to follow-up, as were the four patients about whom no information was received from the family doctors. Four patients were reported to have died, and this meant that there remained 38 about whom information could be obtained. Twenty of these were thought to be too frail to travel to the hospital for assessment, which was therefore carried out by the family doctor. Eighteen were assessed as having a good result, while one patient was reported to have a cystocele and another to have an enterocele. Eighteen patients were asked to attend at our own clinic and were examined by one of us (E. G. R.). Sixteen of them were seen to have a good operative result. They all said that the quality of their life had improved since the operation, and most of them expressed regret that the operation had not been carried out at an earlier age. One patient had a rather poor operative result but would not admit to any symptoms, and the remaining patient had developed an enterocele which was giving rise to symptoms.

It seems, then, that $68 \%$ of the original group were still alive and comfortable and did not show any sign of recurrence two to five years after the operation. Seven patients were known to have died, and one of these has already been described as having died in the immediate postoperative period from a cerebrovascular accident. Both patients who had been unable to attend at the initial follow-up because of confusional states were dead within 12 months, one in uraemic coma (she had suffered from renal failure because of a third-degree procidentia before operation) and the other from a cerebrovascular accident. One patient, who had a simple anterior and posterior colporrhaphy, was found to have a malignant ovarian tumour six months after the operation and died shortly after laparotomy from extensive metastases. One of the patients with diabetes mellitus had a cerebrovascular accident two years after the operation and died three months later. An overweight patient died following a myocardial infarct one year after the operation, and the patient who was known to have carcinoma of the breast died from extensive metastases at about the same time. From the reports of the family doctors it would appear that these patients spent their last few months in much more comfort as a result of the operation.

\section{Discussion}

The number of elderly women in the United Kingdom is increasing steadily, and the problem of the management of prolapse in these cases becomes greater each year. It is noi unusual for a reasonably healthy woman in this age group to become housebound because of the inconvenience and discomfort associated with prolapse. We fully agree with Kosmak (1942), who suggested that fitness for operation is less a matter of years than of physical competence. Payne (1952), Douglas and Studdiford (1953), Fell (1963), and Bentzen and Anker (1964) have all emphasized that operative repair for prolapse can be carried out with little risk and with great benefit to women in their declining years; most of their patients were below the age of 75 . With improvement in the general standard of health and greater longevity more and more women over the age of 75 are admitted to gynaecological wards with severe degrees of prolapse. It is these women in the over-75 age group who cause the gynaecologist so much anxiety. Our experience over the past few years has convinced us that we are right in thinking that these elderly patients stand vaginal plastic operations quite well. The immediate mortality is low, and most derive great benefit from operation. It was very gratifying to learn from family doctors and relatives that for many of these women the last few months or years of life were made much more comfortable by plastic repair operations. This is in contrast to the discomfort and miseries so often associated with the end-stages of a " pessary life."

The choice of surgical procedure in these elderly patients is of some interest. It can be seen from Table II that during the period 1960-4 the staff favoured the Fothergill (Manchester) type of repair for severe degrees of prolapse. In a few cases Le Fort's operation was done during the first year or two of the period, but this procedure is now rather out of favour in our department ; firstly because of the failure rate, and secondly it has become obvious that these older women stand a Fothergill repair or vaginal hysterectomy very well. In the past two years the tendency has been towards more vaginal hysterectomies in this group of elderly women. We should like to stress the importance of careful preoperative assessment and a high standard of postoperative care (including physiotherapy) in the management of this group of patients.

\section{Summary}

The management of prolapse in elderly women presents special problems, for many are frail or have important associated medical conditions. Palliative treatment with some form of vaginal pessary is apt, in our experience, to become a burden rather than a help during the last months or years of life, and may give rise to serious complications.

In the belief that elderly women stand operative treatment surprisingly well, it has long been the policy in the gynaecological department in the Royal Victoria Infirmary to offer surgery where at all possible rather than use vaginal pessaries.

A study of 50 patients over the age of 75 years, operated on for prolapse in the unit during the five-year period 1960-4, 
has shown that the immediate mortality is low, and that most patients derive great benefit from operation.

It is gratifying to learn from family doctors and from relations that for many of these women the last few months or years of life were made much more comfortable by plastic repair operations.

We are grateful to our consultant colleagues, Mr. Frank Stabler, Mr. Derek Tacchi, and Mr. Denys Fairweather, for permission to publish details about cases admitted under their care.
REFERENCES

Bentzen, H., and Anker, H. (1964). 7. Oslo Cy Hosp., 14, 85.

Binnie, G. A. C. (1964). Brit. med. 7., 2, 554.

Douglas, G. W. and Studdiford, W. E, jun. (1954). Amer. 7. Obster. Gynec., 68, 456

Fell, M. R., (1963). Lancet, 1, 799.

Kosmak, G. W. (1942). Amer. Ұ. Obstet. Gynec., 44, 897.

McCullagh, McK. (1955). F. Obstet. Gynaec. Brit. Emp., 62, 599.

McElin T. W., and Paalm, R. (1959). Amer. F. Obstet. Gynec., 78 643.

Payne, W. R. (1952). Ibid., 63, 317.

Pritchard, J. G. (1961). Lancet, 1, 172.

Russell, J. K. (1961). Brit. med.' Y., 2, 1595.

\title{
Molecular Composition of Transfusion Dextran
}

\section{A Report to the Medical Research Council's Blood Transfusion Research Committee*}

\author{
C. R. RICKETTS, † D.SC
}

Brit.med. F., 1966, 2, 1423-1426

The persistence of dextran in the circulation after its intravenous injection depends upon the molecular-weight distribution; smaller molecules are quickly excreted, while larger ones stay and maintain the plasma volume. As molecular weight increases the interaction of dextran molecules with proteins and cells increases. Allergic reactions and increases in bleeding-time have been ascribed to the larger molecules. Moreover, dextran molecules large enough to remain in the circulation for what may be considered to be a useful time tend to cause red cells to adhere together, forming rouleaux.

The dextran used in this country, dextran B.P., has a higher average molecular weight $(150,000)$ than is advocated elsewhere. This confers the advantage of ensuring a satisfactorily long duration of plasma-volume expansion, but it does carry with it the disadvantages referred to in the previous paragraph. Whether or not increased aggregation of red cells is a serious disadvantage remains undecided after 10 years or more of using this dextran.

In the past few years, however, observations of blood-flow in animals have underlined the possible ill effects (Gelin and Zederfeldt, 1961) of high concentrations of dextran of high molecular weight upon the free flow of blood in capillaries through excessive rouleaux formation (Thorsén and Hint, 1950). Microcirculatory and histological investigations have been made on the aggregation of red cells by dextrans (Stalker, 1961, 1964). "Sludging" of the blood and blocking of capillaries have been observed and recorded on cine-film in rabbits, both normal and shocked, which had been given dextran B.P., but these effects occurred to a much less degree after infusion of the dextrans of lower average molecular weight used elsewhere. The degree of aggregation produced by dextran B.P. caused significant histological damage of hypoxic type, particularly in the liver and myocardium, while the dextrans of lower molecular weight caused little or no damage. It is

- Members of the Committee were: Professor P. L. Mollison (chairman), Dr. J. P. Bull, Dr. R. J. Drummond, Sir Alan Drury, Dr. R. A. Kekwick, Dr. J. C. Kelsey, Dr. J. F. Loutit, Professor R. G. Macfarlane, Professor M. Maizels, Dr. W. d'A. Maycock, Dr. A. E. Mourant, Professor W. D. M. Paton, Professor T. A. J. Prankerd, Dr. J. Wallace, Dr. K. L. G. Goldsmith (secretary).

The work was done with the collaboration of Mr. A. I. Evans The work was done with the collaboration of Mr. A. J. Evans
and Dr. J. Kohn, Queen Mary's Hospital, Roehampton; Dr. J. P. and Dr. J. Kohn, Queen Mary's Hospital, Roehampton; Dr. J. P. Bull, Mr. J. Cason, and Mr. D. Jackson, M.R.C. Burns Research
Unit ; Dr. W. d'A. Maycock, Lister Institute, Elstree ; and Dr. A. L. Stalker, Department of Pathology, University of Aberdeen.

t M.R.C. Industrial Injuries and Burns Research Unit, Accident Hospital, Birmingham. not known whether similar changes occur in man, or, if they do occur, whether they are of any clinical significance.

\section{"Sludging "}

In the interest of obtaining a satisfactory persistence in the circulation it is possible that too much "sludging" has been accepted. What could be done to minimize sludging while still retaining a satisfactory persistence in the circulation? A quantitative answer can be obtained from previous experimental work.

No way is known of assessing quantitatively the sludging which occurs in vivo. In vitro rouleaux formation causes an increase in the rate of sedimentation of red cells from a suspension. This rate measured under standardized conditions is the simplest quantitative measurement of the effect of dextran on red cells. It is well known that the larger dextran molecules have the biggest effect on the red-cell sedimentation rate, and in Fig. 1 some earlier data (Hardwicke et al., 1950) are replotted to illustrate that dextrans with intrinsic viscosity below about 0.25 have no effect on sedimentation rate, but above this there

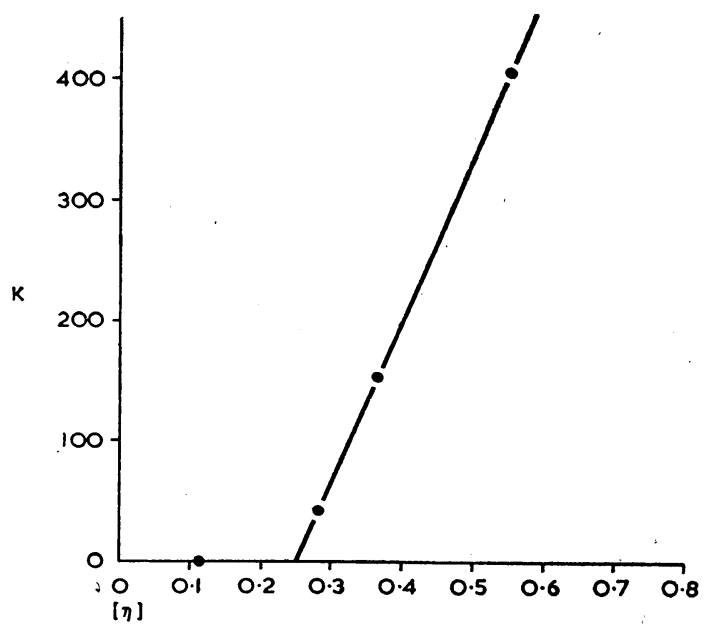

FIG. 1.-Relation between red-cell sedimentation rate (K) and intrinsic viscosity $(\eta)$ of dextran. Hardwicke and Squire (1952). C Calculated log. $K$ for dextran fractions with the intrinsic viscosities shown. 